\title{
High philopatry rates of Yellow-legged Gulls in the southeastern part of the Bay of Biscay
}

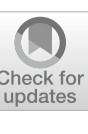

\author{
Sergio Delgado* (D), Alfredo Herrero, Asier Aldalur and Juan Arizaga
}

\begin{abstract}
Background: Philopatry rate is one of the main factors shaping population dynamics in colonial seabirds. Low rates of philopatry are linked to populations with high dispersal, while high rates are linked to populations with a very high spatial structure pattern (i.e., metapopulations). The Cantabrian Yellow-legged Gull (Larus michahellis) population is considered to be resident, with relatively low dispersal rates. Precise estimations of its philopatry rates are however still lacking. Here, we aimed to estimate philopatry rates in the main Yellow-legged Gull colonies of the province of Gipuzkoa, in the southeastern part of the Bay of Biscay.

Methods: We analysed 734 resightings, during the breeding season at the colonies of Getaria, Santa Clara and Ulia, relative to a total of 3245 individuals ringed at birth in these same colonies during a period of 13 years. These data were analysed using Multi-State Recapture models in MARK.

Results: After controlling survival and resighting probability, the average dispersal rate among colonies was 4\% $( \pm \mathrm{SD}=2 \%)$ when individuals are immature, decreasing to $1 \pm 1 \%$ ) for adult breeding gulls (i.e., philopatry rate was 99\%). Annual survival rates were assessed to be $0.27 \pm 0.02$ for birds in their first year of life and $0.87 \pm 0.01$ for older individuals. The probability of observing immature birds in the colonies was $0.08 \pm 0.01$, as compared to $0.21 \pm 0.02$ in adult birds.

Conclusions: We obtained evidence of extremely high local philopatry rates, clearly within the upper limit found in gulls. A high philopatry favour a speciation in these species who are vulnerable to obtain the main food source (landfills and fishing discard) which are transforming under new ecological process.
\end{abstract}

Keywords: Dispersal rates, Metapopulation, Philopatry, Ringing, Survival, Seagulls

\section{Background}

In population dynamics, philopatry is the habit by which individuals show fidelity to a site, hence natal philopatry would refer to those breeding in or close the place where they were born. Recruitment, however, refers to new individuals joining a population, either by birth or by immigration, thus involving philopatric specimens, together with those that, coming from abroad, also settle (recruit) in a place to breed (e.g., Croxall and Rothery 1991). Note, therefore, that this definition approximately

\footnotetext{
*Correspondence: sdelgado@aranzadi.eus
}

Department of Ornithology, Aranzadi Sciences Society, Zorroagagaina 11, 20014 Donostia, Spain fits to the one provided by Pradel (1996), where recruitment is shown to be equivalent to survival in reverse, and can be carried out by inverting capture histories. In colonial birds, therefore, we can calculate the degree of philopatry to natal sites (i.e., to origin colony), i.e., the extent (or rate) to which birds from given colonies return (recruit) to their natal colony (Pradel et al. 1997; Hafner et al. 1998; Oro et al. 2013). If we call this last concept 'local' recruitment, it can be then stated as a synonym of philopatry. The local recruitment among close-by wellestablished colonies has been one of the least known aspects on seabird biology (Gaston 2004), though the body of studies dealing with this subject is increasing (Bosch et al. 2019; Davis et al. 2019; McKnight et al. 
2019). The analysis of local recruitment rates in colonial seabirds is called to play a very relevant role in our comprehension of the dynamics and demographic factors driving seabird populations (Spear et al. 1998; Cam et al. 2002; Payo-Payo et al. 2015).

Recruitment rates in gulls can differ greatly both interand intra-specifically. In general, local recruitment rates will be higher in colonies that grow fast (Oro and Pradel 2000) and that have not reached their maximum carrying capacity (Newton 1998, 2013). Or when birds find cues indicating good conditions, such as a high reproductive output (Cadiou et al. 1993, 1994), high colony size (Oro and Pradel 2000), or high food availability (Spear et al. 1995). Abnormally high mortality rates in adult birds would promote local recruitment as well (Votier et al. 2008) due to the occurrence of vacant places within the colonies. By contrast, these rates will decrease when a colony shows density-dependence (e.g., saturation of breeding places) (Coulson and Coulson 2008) or other external factors that will promote natal dispersal, such as culling programs carried out in the colonies (Chabrzyk and Coulson 1976; Parsons and Duncan 1978).

The Yellow-legged Gull (Larus michahellis) is the most abundant gull in the southwestern Palaearctic (Olsen and Larson 2004). Its abundance is linked to the high availability of food subsidies from landfills or fish discards. Overall, this superabundance of food, that can be very high at a local scale, is considered to foster sedentary habits and reduce dispersal processes to a minimum (Gilbert et al. 2016). In such a scenario, gulls would be expected to show high local recruitment rates, as they would tend to show a high degree of philopatry to those colonies where they find cues indicating good conditions (Gaston 2004). Previous research with the species has assessed local recruitment rates under scenarios where culling programs were active (Bosch et al. 2000, 2019) or using reference estimates from other gull species of similar ecology (Brooks and Lebreton 2001), but where, again, the colonies were subject of culling (Chabrzyk and Coulson 1976; Parsons and Duncan 1978). Therefore, there is still a gap of knowledge on this topic.

Our aims in this work were to: (1) estimate natal philopatry rates in a Yellow-legged Gull population nonintervened by culling consider the local recruitment and the philopatry of adults (with the immigration rate), and (2) survival, in order to test whether high philopatry rates might be linked with low survival in adults since these low rates could facilitate vacant places within the colony which would be available for new breeders (Votier et al. 2008). A priori, we hypothesize high local philopatry rates, since previous works on this population have shown very low dispersal and short-range movements from breeding colonies (Arizaga et al. 2010; Egunez et al.
2017). To address this work, we used data collected over a period of 13 years in three Yellow-legged Gull colonies from the Bay of Biscay (Spain).

\section{Methods \\ Study area and data collection}

This study was carried out in the most important Yellowlegged Gull colonies from Gipuzkoa (North of Spain; from east to west): Ulia $\left(43^{\circ} 20^{\prime} \mathrm{N}, 1^{\circ} 57^{\prime} \mathrm{W}, 1.25 \mathrm{ha}\right)$, with 660 adult breeding pairs (last census from 2017); Santa Clara $\left(43^{\circ} 19^{\prime} \mathrm{N}, 1^{\circ} 59^{\prime} \mathrm{W}, 3.28 \mathrm{ha}\right)$, with 100 pairs; and Getaria $\left(43^{\circ} 18^{\prime} \mathrm{N}, 2^{\circ} 12^{\prime} \mathrm{W}, 0.7 \mathrm{ha}\right)$, with 165 pairs. The distance from Ulia to Getaria (the two colonies situated in the two furthest coordinates) is roughly $20 \mathrm{~km}$.

A variable number of chicks were ringed within each colony on a yearly basis since 2005 (Ulia and Santa Clara) or 2006 (Getaria). Overall, up to 2018, we ringed 3285 chicks (for details see Table 1 ). The chicks were ringed at the age of ca. 20 days (range: ca. 15 to $>30$ days), with both a metal ring and a Darvic ring with an alphanumeric code (red ring with four white numbers/letters), with no differences among years or colonies. Previous study in Ulia breeding colony shows a pre-fledging survival of $60 \%$ per chick, conditioned to hatching date (Delgado and Arizaga 2017). Together with this task, we also compiled all the re-sighting data (ring-readings) obtained across the entire year, both by our teams and by fellow birdwatchers. However we only selected those obtained in the colonies during the breeding period and comprised a 3-month period from April (eggs' laying) to June (grown chicks almost ready to fledge). We assumed that adult individuals found inside the colonies were breeding. Overall, up to 2018, we collected 853 readings of 398 individuals, but 111 gulls had more than one sighting in a year, hence we removed 119 readings from the data set, resulting in 734 resightings (Table 1 ). In four occasions $(0.46 \%)$, an individual bird was seen in the same year in different colonies, we selected the resighting from the original colony or the one closer to it.

\section{Statistical analyses: philopatry models}

We used the software Mark (White and Burnham 1999) to estimate local recruitment rates in each of the three study colonies. In particular, we used multi-state recapture models (Lebreton et al. 2009). Before starting to build any model, we tested for the fit of the data to Arnason-Schwartz assumptions. We used for that a goodness of fit test ran in the software U-CARE (Choquet et al. 2009). The global GOF test was non-significant $\left(\chi^{2}=44.14 ; \mathrm{df}=80 ; P>0.05\right)$, test $3 \mathrm{G}$ for trap-dependence $\left(X^{2}=29.59 ; \mathrm{df}=58 ; P>0.05\right)$ was not significant and test $M$ for transients $\left(\chi^{2}=14.56 ; \mathrm{df}=12 ; P>0.05\right)$. Our models provided three different parameter estimates: (1) 
Table 1 Number of chicks ringed and subsequently number of different encounters (resightings) per colony along the period 2005 to 2018

\begin{tabular}{|c|c|c|c|c|c|c|}
\hline \multirow[t]{2}{*}{ Year } & \multicolumn{2}{|l|}{ Getaria } & \multicolumn{2}{|c|}{ Santa Clara } & \multicolumn{2}{|l|}{ Ulia } \\
\hline & Ringed & Resightings & Ringed & Resightings & Ringed & Resightings \\
\hline 2005 & 0 & - & 23 & - & 17 & - \\
\hline 2006 & 30 & 0 & 69 & 0 & 129 & 2 \\
\hline 2007 & 10 & 12 & 85 & 6 & 202 & 0 \\
\hline 2008 & 38 & 0 & 55 & 5 & 194 & 5 \\
\hline 2009 & 20 & 27 & 50 & 12 & 265 & 7 \\
\hline 2010 & 59 & 21 & 42 & 18 & 221 & 38 \\
\hline 2011 & 32 & 6 & 37 & 0 & 129 & 17 \\
\hline 2012 & 63 & 9 & 86 & 4 & 130 & 22 \\
\hline 2013 & 50 & 10 & 54 & 16 & 68 & 66 \\
\hline 2014 & 50 & 11 & 59 & 10 & 151 & 31 \\
\hline 2015 & 50 & 0 & 35 & 0 & 141 & 12 \\
\hline 2016 & 33 & 15 & 40 & 12 & 162 & 35 \\
\hline 2017 & 33 & 5 & 27 & 9 & 81 & 37 \\
\hline 2018 & 49 & 31 & 52 & 28 & 164 & 195 \\
\hline
\end{tabular}

The number of chicks ringed in total is 3285

movement rate among sites (states), $\psi$; probability of moving from a site (colony) a to b, contingent on survival. Applied to our colonies the parameter $\psi$ may be the probability of a bird ringed as a pullus in colony a to be subsequently seen in colony b; (2) survival, $S$; probability of surviving from year $t$ to year $t+1 ; S$ can be calculated for each site (colony); (3) encounter rate, $p$; probability of detecting a bird which is alive in a site. Note that, concerning $S$, what we estimate here is the apparent local survival, because dispersal outside the colonies will appear as mortality.

In Mark, the models were built under the 'multi-state recaptures only' framework. For that, 'recaptures' (i.e., resightings) from Ulia were coded as 1, Santa Clara as 2, and Getaria as 3. The distance between colonies was: Ulia-Santa Clara, 3.54 km; Ulia-Getaria, 19.60 km; Santa Clara-Getaria, $16.32 \mathrm{~km}$.

First, we built a model where all the parameters (abbreviated as $\psi, S, p$ ) were constant (.) or time dependent $(t)$. Afterwards, we ran a set of alternative models considering an effect of age, colony, and age and colony on the parameter estimates. We considered up to three age categories: $2 \mathrm{a}, 3 \mathrm{a}$ and $4 \mathrm{a}$. $2 \mathrm{a}$ refers to models assuming a difference between two age categories (birds in their first year of life and older birds); 3a refers to models assuming a difference between birds in their first and second year, and older birds; 4 a refers to models assuming a difference between birds up to their third-year of life (immatures), and older birds (adults). Given that most birds hatch by the end of May or early June (Arizaga et al. 2012), a year was considered to last from June to the end of May of the subsequent year. To run such models: (1) we started by fixing $\psi$ and $S$ as constant and time dependent, and testing for the best options fitting on $p$. Alternative models were ranked in relation to their small sample sizecorrected Akaike values (AICc; Burnham and Anderson 1998); models differing in less than 2 AICc values were considered to fit to the data equally well (Burnham and Anderson 1998); (2) Once we found the model best fitting on $p$, we repeated a similar process on $S$, and, finally, on $\psi$.

\section{Results}

Out of 3285 chicks ringed from 2005 to 2018, 398 (12\%) were seen in the colonies 1 or more years after-fledging (Table 1). Most resightings of ringed gulls were detected when the gulls were adults $(n=653$; note here than many individuals were seen more than once); by contrast, a small fraction of the birds were seen in the colonies as immatures $(n=93)$ (Table 2$)$. The proportion of resightings of adults in any colonies was higher in Ulia (95.9\%) as compared to Santa Clara $(77.6 \%)$ or Getaria $(77.5 \%)$ (for further details see Table 2). Out of these 398 birds, 205 (51.5\%) were observed only once, whilst 193 (48.5\%) were seen in more than a single breeding period. The number of gulls found in a colony different from the natal one was just 18 (4.6\%) (Table 2); these birds were seen in 64 occasions. Only one individual was observed to visit the three sampling colonies, and just four out of these 398 birds were found in more than one colony.

From 28 models tested in total, only one was detected to fit the data better than the rest (Table 3). The second 
Table 2 Number (percentage in brackets) of resightings within each colony (columns) in relation to the origin colony (rows)

\begin{tabular}{|c|c|c|c|c|c|c|}
\hline \multirow{2}{*}{$\begin{array}{l}\text { Age class } \\
\text { Origin colony }\end{array}$} & \multicolumn{3}{|c|}{ Immatures } & \multicolumn{3}{|l|}{ Adults } \\
\hline & Getaria & Santa Clara & Ulia & Getaria & Santa Clara & Ulia \\
\hline Getaria & 25 (92.6\%) & $6(18.7 \%)$ & $9(26.5 \%)$ & 107 (97.3\%) & $16(13.1 \%)$ & 15 (2.8\%) \\
\hline Santa Clara & $2(7.4 \%)$ & $26(81.3 \%)$ & $3(8.8 \%)$ & $3(2.7 \%)$ & $100(82.0 \%)$ & $4(0.7 \%)$ \\
\hline Ulia & 0 & 0 & 22 (64.7\%) & 0 & $6(4.9 \%)$ & 509 (96.4\%) \\
\hline
\end{tabular}

Immature gulls comprise birds of up to 3 years of life; older birds have been considered as adults

Table 3 Best-ranked models used to estimate a total of three demographic parameter estimates: local recruitment rates, $\psi$; annual survival, $S$; encounter rate, $p$

\begin{tabular}{|c|c|c|c|c|c|}
\hline Models & AICc & $\triangle \mathrm{AICC}$ & AICc weight & $n_{\mathrm{p}}$ & Deviance \\
\hline$\psi($ colony $+4 a), S(2 a), p($ colony $+3 a)$ & 5665.27 & 0 & 0.9995 & 18 & 1735.92 \\
\hline$\psi(4 a), S(2 a), p($ colony $+3 a)$ & 5680.45 & 15.18 & 0.0005 & 10 & 1767.22 \\
\hline$\psi($ colony), $S(2 a), p($ colony $+3 a)$ & 5696.30 & 31.08 & 0.0000 & 14 & 1775.02 \\
\hline$\psi(),. S(t), p(t)$ & 6359.11 & 693.84 & 0.0000 & 54 & 2356.37 \\
\hline$\psi(),. S(),. p()$. & 6367.65 & 704.52 & 0.0000 & 7 & 2460.45 \\
\hline
\end{tabular}

For comparison, we also add the model with constant and time-dependent parameter estimates. Conducted models consider either a constant, colony and/or agedependent effect on parameter estimates. Age categories have been lumped into $2 \mathrm{a}$, $3 \mathrm{a}$ or $4 \mathrm{a}$. $2 \mathrm{a}$ refers to models assuming a difference between two age classes (birds in their first calendar year and older birds); 3a refers to models assuming a difference between birds in their first and second year, and older birds; 4a refers to models assuming a difference between birds up to their third-year of life, and older birds

AICC small sample sizes-corrected Akaike values, $\triangle A I C C$ difference of AICC values in relation to the first model, $n_{\mathrm{p}}$ number of parameters

model was found to have an AICc value 15 units higher than the first one, as also the third-ranked model had (Table 3). The probability of moving between nearby colonies was age-dependent, it differed among colonies (Fig. 1), and was very low overall $(0.025,2.5 \%)$. In immatures, such flow rates ranged from $0.01(1 \%)$ to $0.09(9 \%)$ (for details see Fig. 1). In adults, such rates were even smaller, being virtually close to zero (Fig. 1), indicating that, once established in a colony, an adult was very unlikely to move to another one.

Regarding survival estimation, we observed that this parameter varied between two age classes, whilst it was not colony-associated. Annual survival in the first-year gulls was 0.27 (95\% CI 0.24, 0.31), increasing up to a mean of 0.86 ( $95 \%$ CI $0.84,0.88$ ) in older birds (> second-year gulls, Fig. 2). Finally, encounter rates differed between age classes and colonies (Fig. 3), being lower in immatures $(<15 \%)$, and in the Santa Clara colony, and higher in adults and the colony of Ulia (Getaria showed intermediate values; Fig. 3).

In the first one, local fidelity rates varied among colonies and in relation to age classes. Overall (birds older than 4 years $)$, these rates ranged from $0.98( \pm \mathrm{SE}=0.014)$ to $0.99 \pm 0.041$ in adults, being only slightly smaller in Getaria (Fig. 1). In immature gulls, local philopatry rate varied more markedly among colonies, from $0.88 \pm 0.023$ in Santa Clara to $0.92 \pm 0.010$ in Getaria or $0.95 \pm 0.001$ in Ulia.

\section{Discussion}

This study is one of the few ones analysing local philopatry rates in a Yellow legged Gull population. Our colonies showed extremely high philopatry, with rates, close to $100 \%$. It is true that this result might partly be biased by the fact that our sampling colonies were located close between each other, hence ignoring those birds which might recruit in colonies located at further distances (Coulson and Coulson 2008). However, during the period of 14 years in which this study was carried out, we were notified to have only 21 birds breeding in colonies found at further distances, and all of them located to the west of the western-most colony of Getaria: Lekeitio $(25 \mathrm{~km})$, Bermeo $(44 \mathrm{~km})$, Santander $(130 \mathrm{~km})$. Furthermore, even within our small sampling range in Gipuzkoa, an extremely low number of birds were found to breed in a colony different from the one where they hatched. Overall, evidence supports that the philopatry rates are truly high within the population.

In this research we were not able to estimate the first age of reproduction due to two main reasons: the orography and the fact that most gulls fly when we approach to the colony, which hampers us from confirming whether a certain bird is breeding or not. Age of recruitment, is an aspect that remains for future studies (Porter and Coulson 1987; Cadiou et al. 1994; Spear et al. 1995; Coulson and Coulson 2008; Oro et al. 2013). Therefore, we had to assume that adults were breeding, so by default the first 


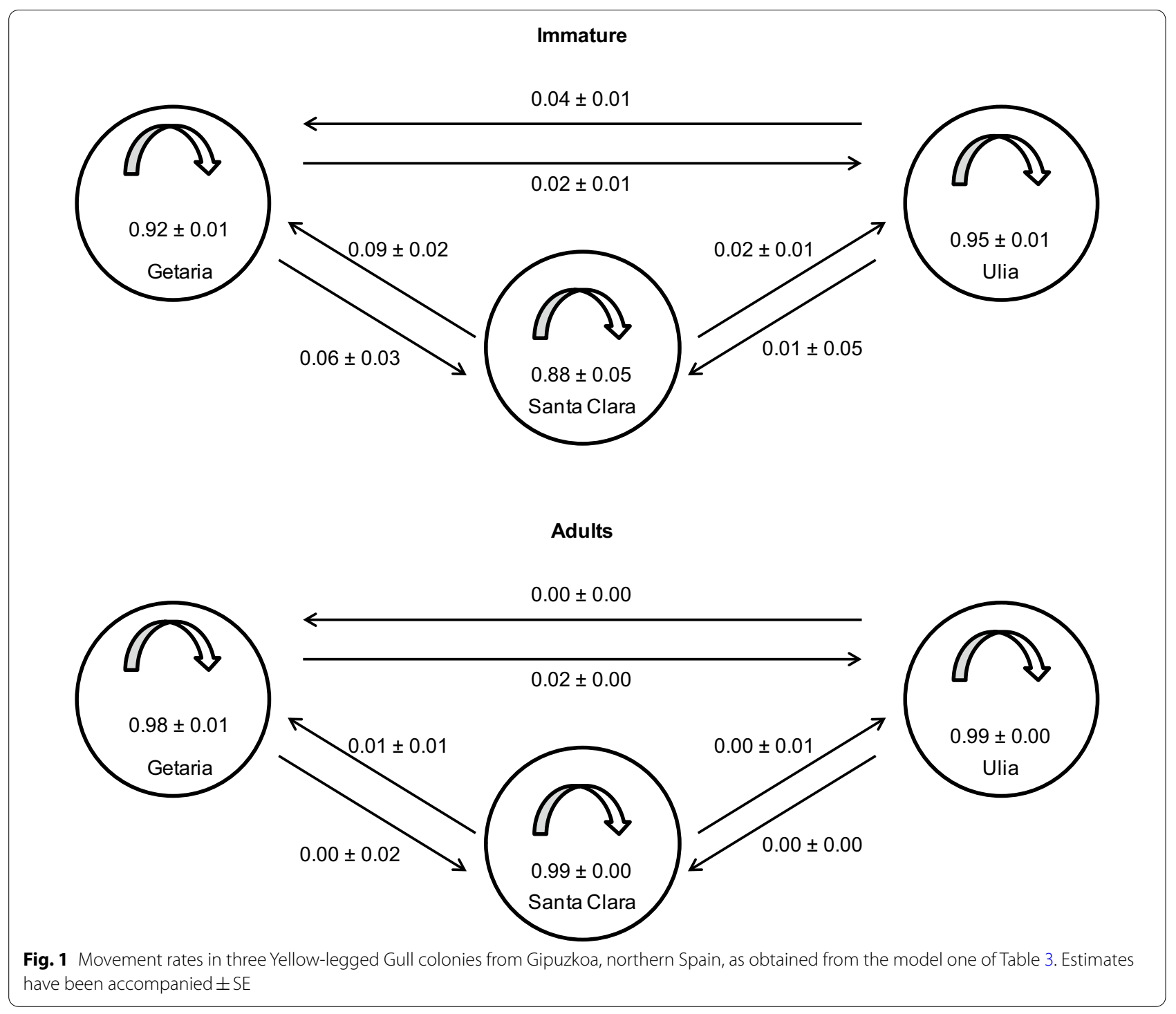

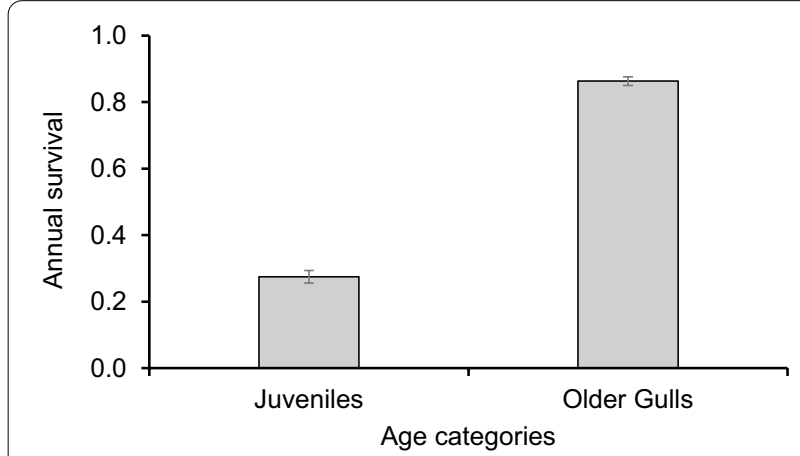

Fig. 2 Annual survival probabilities ( $S$ in models and $\pm S E$ ) of the two main age categories with all the breeding colonies pooled

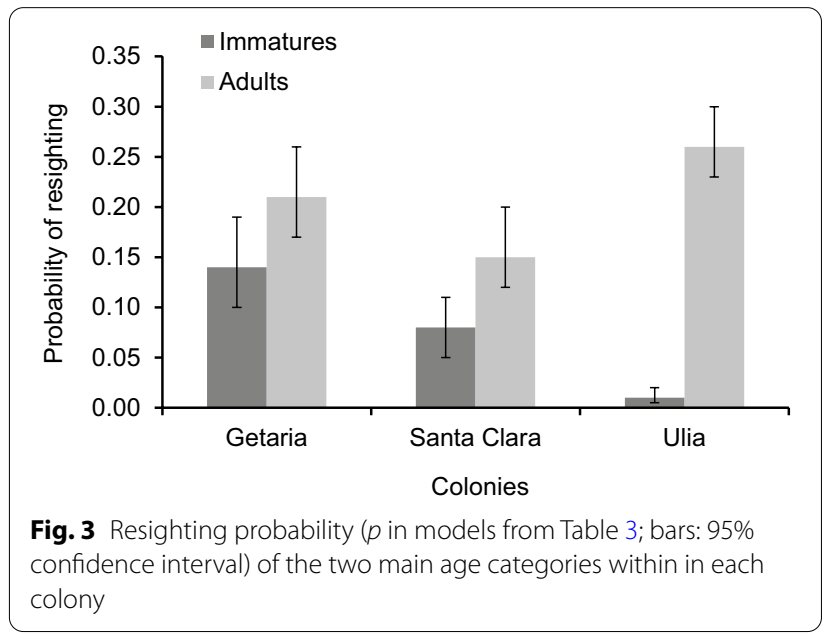


age of reproduction was the fourth year of life, which is the age when the species reaches its sexual maturity (Olsen and Larson 2004). This assumption, however, is rather irrelevant for the conclusions made in this study, since many gulls were sighted several years after their 4th year of life, and the flow among colonies was extremely low.

What we were able to confirm is that immatures were rare within the colonies and this is due to the fact that these birds do not have the need to breed, hence they remain in other areas where they can feed and rest without getting in conflict with adults. The observation of these immature birds within the colonies may be associated to prospecting processes (Dittmann et al. 2005). Even though our data set comprised mostly adult birds, since immatures avoid entering the colonies, therefore, they are much more unlikely to be seen, we still had data to estimate their movement among colonies. During prospection, seabirds visit several sites in order to evaluate the quality and suitability of each colony for future breeding (Dittmann et al. 2005). It is interesting to note here that in Gipuzkoa most immatures were found in their hatching colonies, i.e., the philopatry was high even for these immature birds, suggesting that the prospection was small or very fast, until most birds decided to settle in their origin colony. This suggests that, if prospection exists, our birds may decide at relatively early age recruiting in their natal colony; otherwise, the proportion of resightings at their natal sites would be remarkably lower.

Ultimate causes underlying such a high philopatry in these colonies still remain to be determined, so we cannot do more than advancing some plausible explanations: (1) The familiarity with hatching site may have played a role in this phenomenon (Greenwood and Harvey 1982), but not the colony size (as found by Oro and Pradel 2000), since local recruitment was not higher in Ulia, by far the largest colony within the region; (2) Differences in feeding patterns between the colonies can also influence these high rates of fidelity to natal sites (Enners et al. 2018). In spite of their proximity, our colonies are well known to depend on different feeding resources (Zorrozua et al. 2020), and maybe the juveniles from a given colony would tend to specialize on feeding on those resources exploited by their parents which, consequently, would favour to settle in their hatching sites; (3) The density of the colony has been reported to have a negative effect on recruitment: in areas with high rates of mortality in adults (Duncan 1978), the recruitment for immature individuals is possible in greater number. However, this does not seem to be the case for our colonies. Adults' annual survival was assessed to be almost 90\%, which might be considered a 'normal' value for a Larus gull (Gaston 2004). After applying this estimate in a simple population model, we found that our population was stable or even experiencing a slight, moderate increase (Additional file 1: Appendix S1). In this scenario, it could also be stated that the colonies may have a higher carrying capacity, which would still allow a high philopatry (Duncan 1978); (4) High recruitment rates would also be possible in contexts of very high availability of food subsidies, both due to the existence within the region of a number of fish harbours with high activity (Arizaga et al. 2011; Zorrozua et al. 2020), as well as some still open-air landfills (Egunez et al. 2017; Arizaga et al. 2018). However, the landfills still remaining in the region are expected to be closed in a very short-term period, which is expected to have direct consequences on the dynamics and trophic ecology of this population (Steigerwald et al. 2015; Zorrozua et al. 2019). A sudden food shortage should result in a decreasing reproductive output or survival (Oro et al. 1995), and may also increase dispersal (Arizaga et al. 2014), and it's likely to generate population declines relatively fast (Galarza 2015). As a consequence, local recruitment rates would be lower because natal dispersal would be expected to increase (Oro and Pradel 2000). This incoming new scenario will offer us an excellent opportunity to test for the effect of landfill closure on local recruitment rates.

Globally, our results are within the upper limit of other species where very high rates of local recruitment have been also detected, e.g., in colonies of Audouin's gull (Oro and Pradel 2000). By contrast, other smaller gulls, such as the Black-legged Kittiwake (Rissa trydactyla), were shown to have much smaller local recruitment rates, ranging between 35 and $<10 \%$ (Porter and Coulson 1987; Coulson and Coulson 2008; McKnight et al. 2019). Estimates for the Herring Gull (Larus argentatus) have also reported considerably low local recruitment rates $(<40 \%)$ (Chabrzyk and Coulson 1976; Parsons and Duncan 1978), though in this case the cull of breeding birds could have promoted philopatry rates values abnormally high (Bosch et al. 2000, 2019). The effect of external factors like culling programs on recruitment is important, and the values from some colonies may not be extrapolated to other colonies since this would lead false premises in demographic models (Brooks and Lebreton 2001). Even though the use of mean values is a common practice when building population models, we highlight here the need to be very cautious, and to estimate values obtained from the surveyed colonies always that this is possible.

Local apparent survival estimation values did not vary substantially as compared to previous works (Juez et al. 2015), providing a relatively low value for the first year of life (where the first weeks after fledgling are the most critical ones; Genovart et al. 2017). The real survival value for these first-year birds after fledging could 
indeed be slightly higher, since all these birds were ringed when they were chicks, so pre-fledging mortality should be considered. It is also true, in addition, that pre-fledging survival varies with the chick age, being lower for those birds ringed at an age closer to fledging time (Delgado and Arizaga 2017). Overall, if we assume that that daily mean survival rate from hatching to fledging is ca. 0.98 , and that the chicks were ringed when they were 20 days, their survival from ringing to fledging is roughly 0.668 (Delgado and Arizaga 2017). Thus, survival from fledging to next year could be about 0.40. As we assessed apparent local survival rates, low values in first-year birds might be also interpreted as an artefact associated to dispersal outside our three-colony system. This is possible, and it is probably the case for some individuals, but our population is resident, and the majority of birds remain close to their natal colonies even in their first year of life (Arizaga et al. 2010). Therefore, it can be stated that local survival rates must be rather close to true survival.

The survival estimation of adults felt within the range found for other large gulls (Chabrzyk and Coulson 1976; Pons and Migot 1995). Our models did not detect differences among colonies hence suggesting that, within such a small geographic range, the factors driving the survival of our population may operate at spatial scales larger than a very few kilometres around each colony.

Encounter probabilities were, overall, relatively low (0.15-0.26 in adult birds), showing that finding ringed individuals in the colonies was relatively difficult. A higher sampling effort should help to enhance these results, though, as deducted from the relatively low confidence intervals obtained for the other two parameter estimates, we consider that this higher effort may not have a statistical effect on recruitment or survival. Encounter probabilities were found to be still much lower in immature gulls. Causes underlying this result must focus on the fact that immature specimens tend to remain outside the colonies, often exploiting different foraging areas (Pettex et al. 2019). The colony-dependent variation in these encounter rates is attributed by us to the topography and the accessibility.

\section{Conclusions}

In conclusion, the Yellow legged Gull population breeding in the southeaster part of the Bay of Biscay showed remarkably high philopatry, indicating a high dependency to natal sites. Such rates might be expected to change in a nearby future, where the still existing open landfills will be closed, hence promoting higher dispersal, probably lower survival rates and also decreasing local recruitments.

\section{Supplementary Information}

The online version contains supplementary material available at https://doi. org/10.1186/s40657-021-00271-8.

Additional file 1: Appendix S1. A simple population model to check whether our population was stable, decreasing or increasing (i.e., showed a lambda, $\lambda$, equal, below or above 1).

\section{Acknowledgements}

The Gipuzkoa Regional Council provided the permits to capture and ring the gulls. We are grateful to the volunteers and birdwatchers that, during all these years, have reported sighting data. Two referees provided valuable comments that helped us to improve an earlier version of this work.

\section{Authors' contributions}

SD and JA conceived the study, SD and AA participated in the field work, JA and $\mathrm{AH}$ maintain and provided the data base, SD ran the analyses, SD and JA wrote the manuscript. All authors read and approved the final manuscript.

\section{Funding}

This research was partly funded by the Basque Government and the Gipuzkoa Regional Council. SD benefited from a pre-doctoral fellowship from the Basque Government.

\section{Availability of data and materials}

The datasets used in the present study are available from the corresponding author on reasonable request.

\section{Declarations}

Ethics approval and consent to participate

Our research adheres to local guidelines and appropriate ethical approval.

\section{Consent for publication}

Not applicable.

\section{Competing interests}

The authors declare that they have no competing interests.

Received: 13 January 2021 Accepted: 18 June 2021

Published online: 29 June 2021

\section{References}

Arizaga J, Herrero A, Galarza A, Hidalgo J, Aldalur A, Cuadrado JF, Ocio G. Firstyear movements of yellow-legged gull (Larus michahellis lusitanius) from the southeastern Bay of Biscay. Waterbirds. 2010;33:444-50.

Arizaga J, Aldalur A, Herrero A, Cuadrado JF, Mendiburu A, Sanpera C. High importance of fish prey in diet of yellow-legged gull Larus michahellis chicks from the southeast Bay of Biscay. Seabird. 2011;23:1-6.

Arizaga J, Aldalur A, Cuadrado JF, Díez E, Goikoetxea J, Herrero A, et al. Parámetros reproductores de la gaviota patiamarilla Larus michahellis lusitanius Naumann, 1840 en Gipuzkoa. Munibe. 2012;60:167-74.

Arizaga J, Aldalur A, Herrero A, Cuadrado J, Díez E, Crespo A. Foraging distances of a resident yellow-legged gull (Larus michahellis) population in relation to refuse management on a local scale. Eur J Wildl Res. 2014;60:171-5.

Arizaga J, Zorrozua N, Egunez A. Between the land and sea: how yellowlegged gulls have changed their dependence on marine food in relation to landfill management. In: Mikkola H, editor. Seabirds. InTech: London; 2018. p. 67-8.

Bosch M, Oro D, Cantos FJ, Zabala M. Short-term effects of culling on the ecology and population dynamics of the yellow-legged gull. J Appl Ecol. 2000;37:369-85.

Bosch M, Pocino N, Carrera-Gallissà E. Effects of age and culling on movements and dispersal rates of yellow-legged gulls (Larus michahellis) from a western mediterranean colony. Waterbirds. 2019;42:179-87. 
Brooks EN, Lebreton JD. Optimizing removals to control a metapopulation: application to the yellow legged herring gull (Larus cachinnans). Ecol Model. 2001;136:269-84.

Burnham KP, Anderson DR. A practical information theoretic approach. In: Burnham KP, Anderson DR, editors. Model selection and inference. New York: Springer; 1998.

Cadiou B, Danchin E, Monnat JY, Boulinier T. Régulation par la recrutement, la fidélité et la non-reproduction chez un oiseau colonial, la mouette tridactyle (Rissa tridactyla). Rev Ecol. 1993;48:163-74.

Cadiou B, Monnat JY, Danchin E. Prospecting in the kittiwake, Rissa tridactyla: different behavioural patterns and the role of squatting in recruitment. Anim Behav. 1994;47:847-56.

Cam E, Cadiou B, Hines J, Monnat JY. Influence of behavioral tactics on recruitment and reproductive trajectory in the kittiwake. J Appl Stat. 2002;29:163-85

Chabrzyk G, Coulson JC. Survival and recruitment in herring gull Larus argentatus. J Anim Ecol. 1976;45:187-203.

Choquet R, Lebreton JD, Gimenez O, Reboulet AM, Pradel R. U-CARE: utilities for performing goodness of fit tests and manipulating CApture-REcapture data. Ecography. 2009;32:1071-4.

Coulson JC, Coulson BA. Measuring immigration and philopatry in seabirds; recruitment to black-legged kittiwake colonies. Ibis. 2008;150:288-99.

Croxall JP, Rothery P. Population regulation of seabirds: implications of their demography for conservation. Bird population studies: relevance to conservation and management. New York: Oxford University Press; 1991.

Davis KL, Karpanty SM, Spendelow JA, Cohen JB, Althouse MA, Parsons KC, et al. Residency, recruitment, and stopover duration of hatch-year Roseate Terns (Sterna dougallii) during the pre-migratory staging period. Avian Conserv Ecol. 2019;14:11.

Delgado S, Arizaga J. Pre-fledging survival in a yellow-legged gull Larus michahellis population in northern Iberia is mostly determined by hatching date. Bird Study. 2017;64:132-7.

Dittmann T, Zinsmeister D, Becker PH. Dispersal decisions: common terns, Sterna hirundo, choose between colonies during prospecting. Anim Behav. 2005:70:13-20.

Duncan N. The effects of culling herring gulls (Larus argentatus) on recruitment and population dynamics. J Appl Ecol. 1978;15:697-713.

Egunez A, Zorrozua N, Aldalur A, Herrero A, Arizaga J. Local use of landfills by a yellow-legged gull population suggests distance-dependent resource explotation. J Avian Biol. 2017. https://doi.org/10.1111/jav.01455.

Enners L, Schwemmer P, Corman AM, Voigt CC, Garthe S. Intercolony variations in movement patterns and foraging behaviors among herring gulls (Larus argentatus) breeding in the eastern Wadden sea. Ecol Evol. 2018;8:7529-42.

Galarza A. Is the population of Cantabrian yellow-legged gull Larus michahellis lusitanius Naumann, 1840 decreasing? 2013/2014 census in Biscay (Basque country). Munibe. 2015;63:135-43.

Gaston A. Seabirds: a natural history. London: T \& AD Poyser; 2004.

Genovart M, Doak DF, Igual JM, Sponza S, Kralj J, Oro D. Varying demographic impacts of different fisheries on three Mediterranean seabird species. Glob Change Biol. 2017;23:3012-29.

Gilbert NI, Correia RA, Silva JP, Pacheco C, Catry I, Atkinson PW, et al. Are white storks addicted to junk food? Impacts of landfill use on the movement and behaviour of resident white storks (Ciconia ciconia) from a partially migratory population. Mov Ecol. 2016;4:1-13.

Greenwood PJ, Harvey PH. The natal and breeding dispersal of birds. Annu Rev Ecol Evol Syst. 1982;13:1-21.

Hafner H, Kayser Y, Boy V, Fasola M, Julliard AC, Pradel R, et al. Local survival, natal dispersal, and recruitment in little egrets Egretta garzetta. J Avian Biol. 1998;29:216-27.
Juez L, Aldalur A, Herrero A, Galarza A, Arizaga J. Effect of age, colony of origin and year on survival of yellow-legged gulls Larus michahellis in the Bay of Biscay. Ardeola. 2015;62:139-50.

Lebreton JD, Nichols JD, Barker RJ, Pradel R, Spendelow JA. Modeling individual animal histories with multistate capture-recapture models. Adv Ecol Res. 2009;41:87-173.

McKnight A, Blomberg EJ, Irons DB, Loftin CS, McKinney ST. Survival and recruitment dynamics of black-legged kittiwakes Rissa tridactyla at an Alaskan colony. Mar Ornithol. 2019:47:209-22.

Newton I. Population limitation in birds. London: Academic Press; 1998.

Newton I. Bird populations. New York: HarperCollins Publishers; 2013.

Olsen KM, Larson H. Gulls of Europe, Asia and North America. London: A \& C Black; 2004.

Oro D, Pradel R. Determinants of local recruitment in a growing colony of Audouin's gull. J Anim Ecol. 2000;69:119-32.

Oro D, Bosch M, Ruiz X. Effects of a trawling moratorium on the breeding success of the yellow-legged gull Larus cachinnans. Ibis. 1995;137:547-9.

Oro D, Hernández N, Jover L, Genovart M. From recruitment to senescence: food shapes the age-dependent pattern of breeding performance in a long-lived bird. Ecology. 2013;95:446-57.

Parsons J, Duncan N. Recoveries and dispersal of herring gulls from the Isle of May. J Anim Ecol. 1978;47:993-1005.

Payo-Payo A, Oro D, Igual JM, Jover L, Sanpera C, Tavecchia G. Population control of an overabundant species achieved through consecutive anthropogenic perturbations. Ecol Appl. 2015;25:2228-39.

Pettex E, Lambert C, Fort J, Dorémus G, Ridoux R. Spatial segregation between immatures and adults in a pelagic seabird suggests age-related competition. J Avian Biol. 2019;50: e01935.

Pons JM, Migot P. Life-history strategy of the herring gull: changes in survival and fecundity in a population subjected to various feeding conditions. J Anim Ecol. 1995;64:592-9.

Porter JM, Coulson JC. Long-term changes in recruitment to the breeding group, and the quality of recruits at a kittiwake Rissa tridactyla colony. J Anim Ecol. 1987;56:675-89.

Pradel R. Utilization of capture-mark-recapture for the study of recruitment and population growth rate. Biometrics. 1996;52:703-9.

Pradel R, Johnson AR, Viallefont A, Nager RG, Cezilly F. Local recruitment in the greater flamingo: a new approach using capture-mark-recapture data. Ecology. 1997;78:1431-45.

Spear L, Sydeman WJ, Pyle P. Factors affecting recruitment age and recruitment probability in the western gull Larus occidentalis. Ibis. 1995;137:352-9.

Spear LB, Pyle P, Nur N. Natal dispersal in the western gull: proximal factors and fitness consequences. J Anim Ecol. 1998;67:165-79.

Steigerwald EC, Igual JM, Payo-Payo A, Tavecchia G. Effects of decreased anthropogenic food availability on an opportunistic gull: evidence for a size-mediated response in breeding females. Ibis. 2015;157:439-48.

Votier SC, Birkhead TR, Oro D, Trinder M, Grantham MJ, Clark JA, et al. Recruitment and survival of immature seabirds in relation to oil spills and climate variability. J Anim Ecol. 2008;77:974-83.

White GC, Burnham KP. Program MARK: survival estimation from populations of marked animals. Bird Study. 1999;46:20-39.

Zorrozua N, Aldalur A, Herrero A, Diaz B, Delgado S, Sanpera C, et al. Breeding yellow-legged gulls increase consumption of terrestrial prey after landfill closure. Ibis. 2019;162:50-62.

Zorrozua N, Egunez A, Aldalur A, Galarza A, Díaz B, Hidalgo J, et al. Evaluating the effect of distance to different food subsidies on the trophic ecology of an opportunistic seabird species. J Zool. 2020;311:45-55. 